\title{
Involvement of the community nurse in the case management of patients with rare diseases
}

\author{
Implicarea asistentului medical comunitar în managementul de caz \\ al pacienţilor cu boli rare
}

\author{
Lidia Manuela Onofrei1,2, Elena Mocanu ${ }^{3}$, Nicoleta loana Andreescu ${ }^{4,5}$, \\ Liliana Ana Tuțăa ${ }^{3}$, Maria Puiu ${ }^{4,5}$ \\ ${ }^{1}$ Școala Doctorală de Medicină, Universitatea „Victor Babeș", Timișoara, România \\ ${ }^{2}$ Coordonator Național al Activității de Asistență Medicală Comunitară, Ministerul Sănătății, România \\ ${ }^{3}$ Facultatea de Medicină, Universitatea „Ovidius", Constanța, România \\ ${ }^{4}$ Departamentul de Morfologie microscopică - Genetică, Centrul de Genomică Medicală \\ Universitatea „Victor Babeș", Timișoara, România \\ ${ }^{5}$ Centrul Regional de Genetică Medicală Timiș, Spitalul Clinic de Urgență pentru Copii \\ „Louis Jurcanu“, Timișoara, România
}

\begin{abstract}
The community nurse activity includes programs, health services and public health actions provided at the community level and is carried out in an integrated system, through collaboration with family doctors' offices, social services and educational services, other medical and social structures, public or private, within the community and the county, including with non-governmental organizations, in order to increase the access of the population belonging to vulnerable groups to medical and social services.

Rare disease is defined as a life-threatening condition or chronic disability that affects less than five out of 10,000 people. Each rare disease affects a small percentage of the population, but due to the fact that over 7,000 different rare diseases are currently described, it is estimated that about $8 \%$ of Europe's population is affected by a rare disease. Most rare diseases, due to the fact that they are rare and do not benefit from treatment, are also called orphan diseases.

It is necessary for the Ministry of Health to strengthen the training program for staff in the community nurse network and to support the development of the community nurse network in achieving case management of rare diseases.
\end{abstract}

Keywords: community nurse, rare diseases, case management

\section{REZUMAT}

Activitatea de asistență medicală comunitară cuprinde ansamblul de programe, servicii de sănătate şi acţiuni de sănătate publică furnizate la nivelul comunităţilor si se desfășoară în sistem integrat, prin colaborarea cu cabinetele medicilor de familie, cu serviciile sociale și servicii educaționale, cu alte structuri medicale și sociale, de stat sau private, de pe raza comunității și a județului, inclusiv cu organizații neguvernamentale, cu scopul creşterii accesului populaţiei apartinând grupurilor vulnerabile la servicii medico-sociale.

Boala rară este definită ca o afecțiune care pune viața în pericol sau provoacă o invaliditate cronică și afectează mai puțin de cinci din 10.000 de persoane. Fiecare boala rară, în parte, afectează un procent mic din populație, dar, ca urmare a faptului că sunt descrise în prezent peste 7.000 de boli rare diferite, se estimează ca aproximativ $8 \%$ din populația Europei este afectată de o boală rară. Majoritatea bolilor rare, ca urmare a faptului că sunt rare și nu beneficiază nici de tratament, mai sunt denumite şi boli orfane.

Este necesar ca Ministerul Sănătății să consolideze programul de instruire pentru personalul din rețeaua de asistență medicală comunitară și să sprijine dezvoltarea rețelei de asistență medicală comunitară în realizarea managementului de caz al bolilor rare.

Cuvinte cheie: asistent medical comunitar, boli rare, management de caz 


\section{INTRODUCERE}

Asistența medicală comunitară cuprinde ansamblul de programe, servicii de sănătate şi acţiuni de sănătate publică furnizate la nivelul comunităţilor, cu scopul creşterii accesului populaţiei - şi în special al grupurilor vulnerabile - la servicii medicale şi socio-medicale $[1,2]$.

Managementul de caz este metoda de lucru obligatoriu utilizată în domeniul îngrijirii pacienților cu boli rare și reprezintă ansamblul de tehnici, proceduri și instrumente de lucru care asigură conectarea pacientului și a familiei acestuia cu toți specialiștii și experții, centrele de expertiză și serviciile medicale, sociale și educaționale de care au nevoie, precum și coordonarea tuturor activităților de îngrijire în comunitate, desfăşurate în interesul superior al pacientului $[2,3]$.

Boala rară este definită ca o afecțiune care pune viața în pericol sau provoacă o invaliditate cronică și afectează mai puțin de cinci din 10.000 de persoane. Fiecare boala rară, în parte, afectează un procent mic din populație, dar, ca urmare a faptului că sunt descrise în prezent peste 7.000 de boli rare diferite, se estimează că aproximativ $8 \%$ din populaţia Europei este afectată de o boală rară. Bolile rare sunt o problemă de sănătate publică pretutindeni în lume. Persoanele cu astfel de boli necesită îngrijiri medicale ultraspecializate, de înaltă calitate și sigure, servicii sociale și sprijin specific [4].

Problematica bolilor rare este o prioritate în strategiile de sănătate naționale, dar necesită și o strategie globală bazată pe cooperare, colaborare și reglementare la nivel mondial - reunirea expertizei și utilizarea eficientă a resurselor disponibile [5].

\section{MATERIAL ŞI METODĂ}

În cadrul acestei lucrări, am efectuat un studiu retrospectiv, analizând raportarea statistică a cazu- rilor de boli rare conform HG 324/2019 pentru aprobarea Normelor metodologice privind organizarea, funcționarea și finanțarea activității de asistență medicală comunitară. Datele necesare realizării acestui studiu au fost descărcate de pe aplicaţia online cu numele de subdomeniu AMCMSR. gov.ro, înscrisă în REGISTRU gov.ro, cu asigurarea protecției datelor cu caracter personal conform legislației în vigoare. Această aplicaţie este un instrument standardizat al Ministerul Sănătății de colectare de date, analiză, planificare, monitorizare și evaluare a serviciilor de asistență medicală comunitară la nivel național și de intervenție în timp real în cazul identificării situațiilor medico-sociale cu risc major [6]. Prelucrarea datelor s-a realizat cu ajutorul aplicaţiei Microsoft Excel.

\section{REZULTATE}

La sfârşitul anului 2020, la nivel național, îşi desfășoară activitatea 1.874 de asistenţi medicali comunitari şi 453 de mediatori sanitari.

Finanţarea activităţii asistenţilor medicali comunitari provine din următoarele surse: 1682 de la bugetul de stat prin Ministerul Sănătății, 105 din proiectul „Crearea și implementarea serviciilor comunitare integrate pentru combaterea sărăciei și a excluziunii sociale", POCU/375/4/22/122607, 56 de la bugetele locale, 12 sunt plătiţi conform legislaţiei pentru starea de alertă, declarată ca urmare a pandemiei COVID-19, tot din bugetele locale ale unităţilor teritorial administrative, și 3 asistenți medicali sunt plătiţi de către UNICEF.

În prezent, pe teritoriul României există 1.880 de unităţi teritorial administrative fără asistenți medicali comunitari. Conform standardelor prevăzute în HG 459/2010, la nivelul întregii ţări, ar mai fi nevoie de aproximativ 3.192 de asistenţi medicali comunitari pentru desfășurarea în condiții

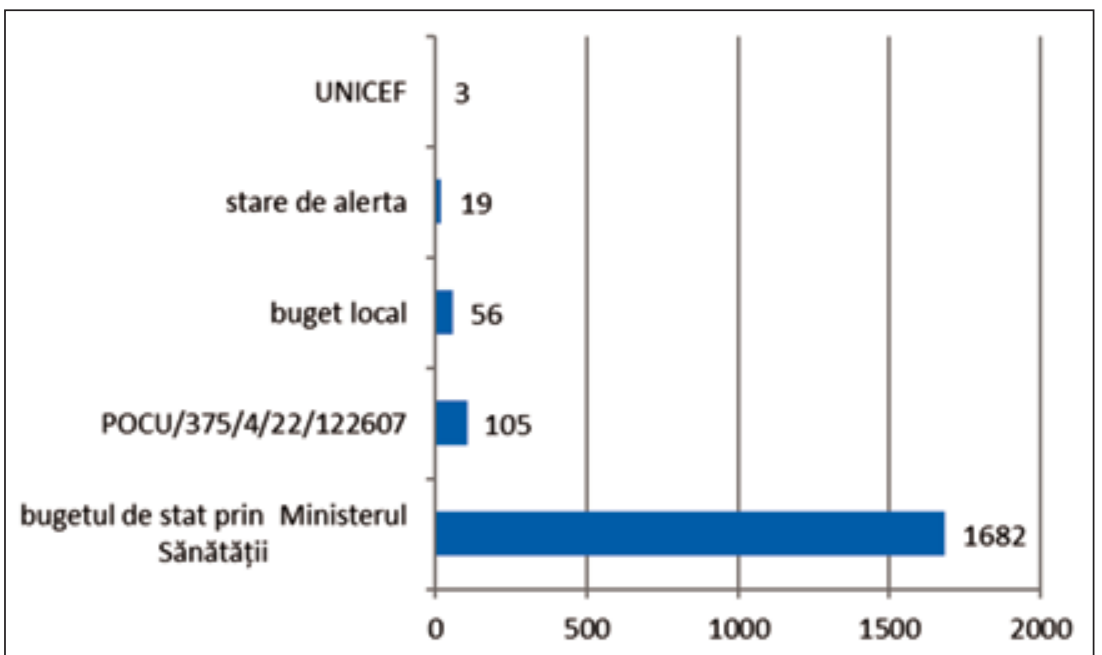

FIGURA 1. Finanțarea activității asistenților medicali comunitari pe teritoriul României în anul 2020 
optime a activităţilor specific în cadrul comunităților [7].

HG 324/2019 pentru aprobarea Normelor metodologice privind organizarea, funcţionarea şi finanţarea activităţii de asistenţă medicală comunitară prevede ca asistenții medicali comunitari să realizeze managementul de caz în cazul bolnavilor cu boli rare, în limita competenţelor profesionale, conform modelului de management de caz. Modelul de management de caz va fi adoptat prin ordin al ministrului Sănătăţii. Până la aprobarea modelului managementului de caz, o parte din personalul ce activează în unele județe a fost inițiat în problematica bolilor rare prin activități în cadrul diferitelor proiecte desfășurate [6].

Din anul 2018, asistenții medicali comunitari identifică și monitorizează pacienții cu boli rare și genetice și îi trimit către medicii de familie și/sau medicii specialiști și către serviciile de asistență socială.

În intervalul 2018-2020, personalul implicat în activităţi de asistenţă medicală comunitară a iden- tificat şi monitorizat 1.030 de pacienţi cu boli rare şi genetice.

Raportarea cazuisticii de pacienți cu boli rare și genetice a fost începută în trimestrul 3 al anului 2018 și așa se explică numărul mic de cazuri în anul 2018, comparativ cu anii 2019 și 2020, când în aplicație a raportat personalul din 39 de județe, $\mathrm{cu}$ excepția județului Braşov, care nu are niciun asistent medical comunitar angajat la nivelul județului, și a județului Ilfov și a municipiului București, unde personalul urmează să raporteze activitatea începând cu anul 2021.

În clusterul „Alte anomalii cromozomiale"“, am inclus: trisomie 18 (sindrom Edwards), anomalii ale cromozomului Y, sindrom Rubinstein Taybi, retinoblastom, nefroblastom, sindrom Beckwith Wiedemann.

Identificarea pacienților cu boli genetice și rare se face de către asistentul medical comunitar în baza diagnosticului pus de medical specialist. Monitorizarea beneficiarilor se face în baza recomandărilor medicilor de familie sau ale medicilor
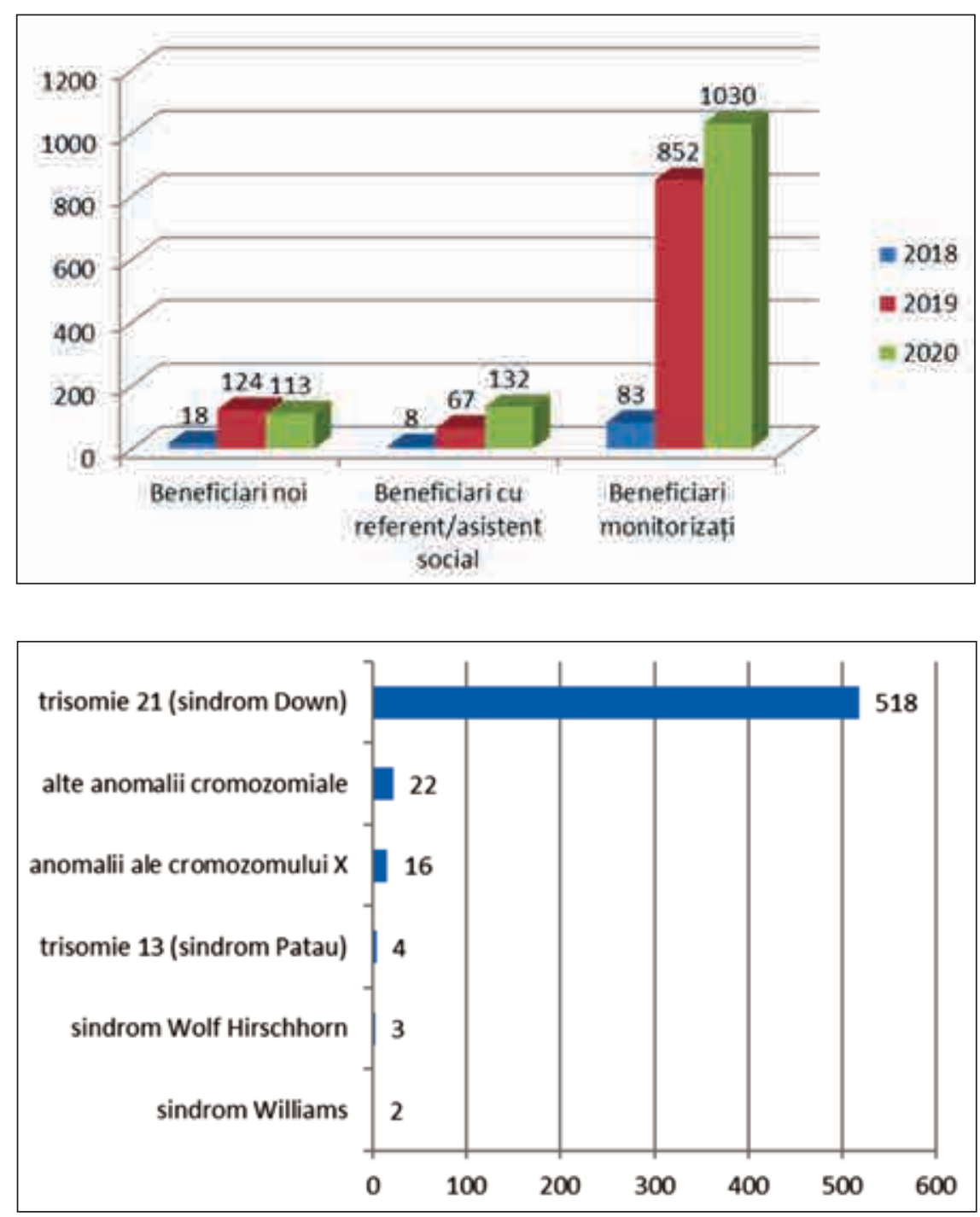

FIGURA 2. Repartiția beneficiarilor serviciilor de asistență medicală comunitară pe teritoriul României în perioada 2019-2020
FIGURA 3. Distributtia cazurilor de boli rare - anomalii cromozomiale depistate şi monitorizate de către asistenții medicali comunitari pe teritoriul României 


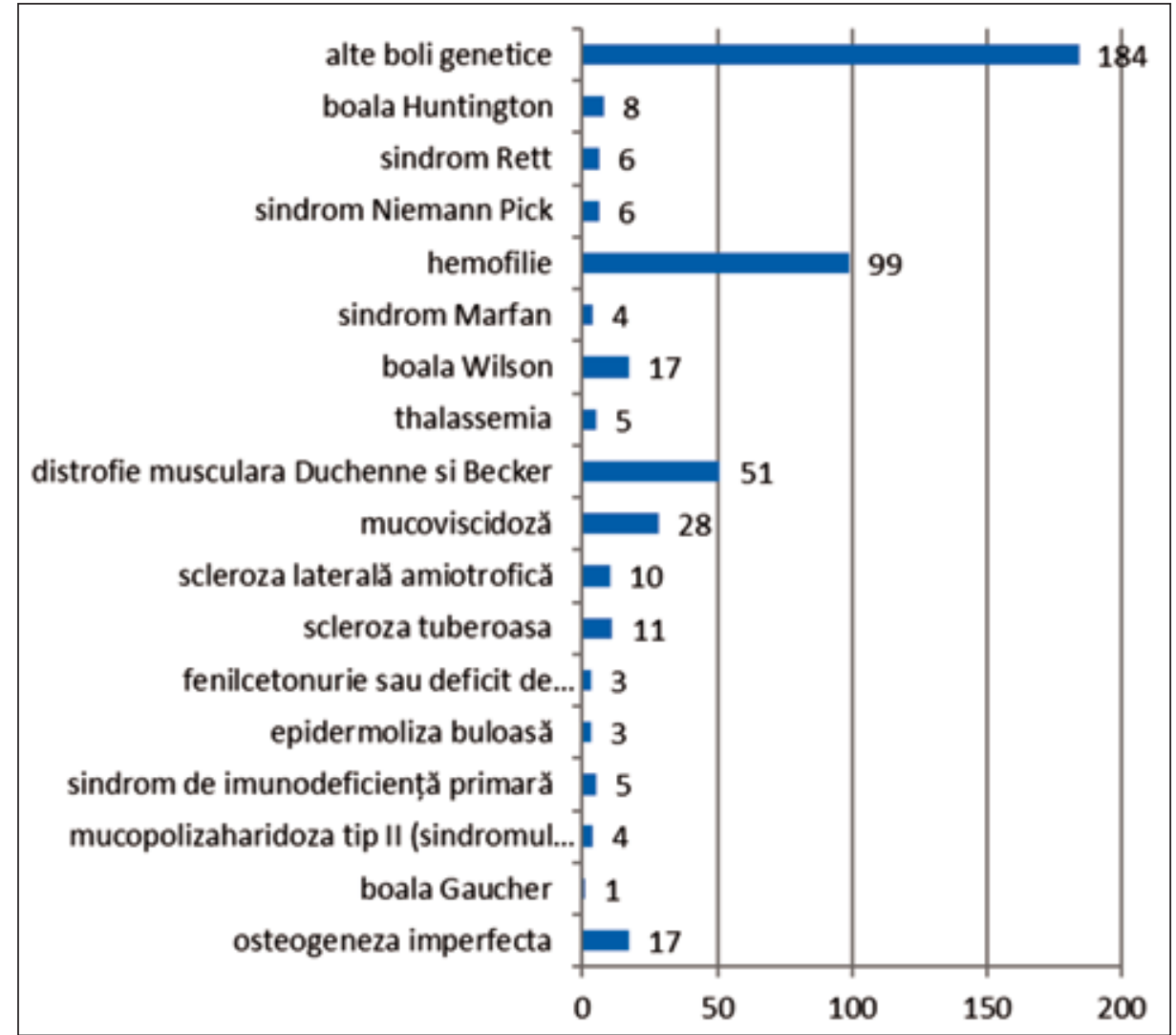

FIGURA 4. Distribuția cazurilor de boli rare - boli genetice depistate şi monitorizate de către asistenții medicali comunitari pe teritoriul României specialiști. Cele mai frecvente cazuri întâlnite în practica curentă a asistentului medical comunitar sunt cele de sindrom Down, care, similar altor boli rare, necesită o colaborare în echipă multidisciplinară.

În clusterul „Alte boli genetice“, am inclus: boala Fabry, boala Pompe, tirozinemie, mucopolizaharidoza tip I (sindromul Hurler), afibrinogenemie congenitală, angioedem ereditar, neuropatie optică ereditară Leber, neurofibromatoză. Toate aceste boli genetice rare necesită o abordare medicală multidisciplinară pentru stabilirea corectă a diagnosticului și a tipului de intervenție.

\section{DISCUȚII}

Activitatea de asistență medicală comunitară a fost inițiată de către Ministerul Sănătăţii în anul 2002, în cadrul unui program pilot desfășurat în 7 județe și municipiul București $[1,8]$. În 2020, aproape întreg teritoriu al țării noastre este acoperit în ceea ce privește desfășurarea activităților de asistență medicală comunitară, excepție făcând județul Brașov, care nu are încadrați astfel de specialiști.

Prin utilizarea managementului de caz pentru pacienţii cu boli rare, se doreşte asigurarea intervenţiilor multidisciplinare şi interinstituţionale, într-un mod organizat, riguros, eficient și coerent pentru pacient, familie/reprezentant legal şi alte persoane importante pentru pacient $[1,3,5,8]$.

Evaluarea atentă a cazului şi analiza sa în echipă multidisciplinară pot identifica într-un timp relativ scurt tipul intervenţiei necesare, în funcţie de statusul medico-socio-economic al beneficiarului $[1,3,5,8]$.

În România, sunt aproximativ 1,3 milioane de pacienţi cu boli rare, iar la nivel european există 30.000.000 de persoane cu astfel de afecţiuni, ceea ce reprezintă peste $8 \%$ din populația de pe continent [9].

În anul 2017, la nivel european, una din 17 persoane suferea de o boală rară, iar la nivel global, peste $90 \%$ dintre pacienții cu boli rare nu au tratament, pe fondul lipsei diagnosticului sau a diagnosticării tardive sau a inexistenţei unui tratament specific pentru boala respectivă $[10,11]$.

În prezent, la nivel internaţional, sunt înregistrate peste 7.000 de boli rare diferite, dintre care $80 \%$ sunt de origine genetică $[9,12]$.

În Europa, o boală este considerată a fi rară dacă afectează 1 persoană din 2.000, iar în SUA o boală este considerată rară dacă afectează 5 persoane la 10.000 de locuitori. Procentul rămâne constant, existând doar o diferențe de exprimare. O boală poate fi rară într-o regiune, dar comună în alta. Acesta este cazul talasemiei, o anemie de cauză genetică, rară în Europa de nord, dar frecventă în regiunea mediteraneană $[13,14]$. 
Conform datelor prezentate pe platforma Orphanet, peste $50 \%$ dintre bolile rare apar la adulți (spre exemplu: boala Huntington, Crohn, Charcot Marie Tooth, scleroza laterală amiotrofică, sarcomul Kaposi sau cancerul tiroidian), dar, pentru multe boli rare, semnele pot fi observate încă de la naştere sau devreme, în copilărie, cum ar fi cazul atrofiei musculare spinale, neurofibromatozei, osteogenesis imperfecta, condrodisplaziilor sau sindromului Rett [13].

În anul 1997, a fost înființată Organizația Europeană de Boli Rare - EURORDIS -, cu scopul de a asigura, într-o colaborare transfrontalieră, o creştere a calităţii vieții celor care suferă de boli rare. În prezent, aceasta are peste 730 de organizații naționale membre din 65 de țări și acoperă peste 4.000 de boli rare diferite [14]. Din anul 2007, și România este prezentă în această organizație, prin intermediul Alianței Naționale pentru Boli Rare (ANBRaRo).

O resursă importantă de informații pentru pacienți și profesioniști este platforma Orphanet, înființată în Franța, în 1997, de către Institutul Naţional Francez pentru Sănătate şi Cercetare Medicală (INSERM). Orphanet manageriază Nomenclatorul de boli rare (ORPHA number), esențial pentru îmbunătățirea vizibilității acestor boli în sistemele de sănătate și în cercetare. În prezent, 40 de țări de pe întreg mapamondul sunt afiliate Ophanet [13].

În anul 2017, au fost aprobate primele Rețele europene de referință (RER), ce reunesc 370 de spitale şi aproape 1.000 de furnizori de servicii medicale din 26 de țări (25 de state membre, plus Norvegia). În România, în prezent, sunt acreditate 27 de centre de expertiză, dintre care nouă sunt deja incluse în RER, însă nu există încă un registru naţional pentru boli rare. Ministerul Sănătății a certificat centre de expertiză pentru boli rare în București, Cluj-Napoca, Timișoara, Craiova, Zalău, Iași, Oradea și Tg. Mureş. Sunt centre de expertiză în boli rare care cooperează cu rețele europene pentru bolile rare și care oferă servicii integrate pacienților.

10 dintre acestea fac parte din rețele europene de referință, ceea ce demonstrează faptul că s-au făcut pași importanți pentru accesul la îngrijire pentru pacienții cu boli rare, ceea ce va determina o îmbunătățire a calității vieții acestor persoane.

Rata de mortalitate a acestor pacienţi este crescută. Principalele cauze de mortalitate sunt aceleași: diagnosticarea târzie și lipsa unui tratament adecvat, acestea fiind accentuate de experiența insuficientă, deficitul de specialiști în genetică medicală, dar și de numărul mic de centre specializate [15].

Majoritatea bolilor rare sunt multisistemice, necesitând o îngrijire multidisciplinară. Bolile rare sunt cronice și, în majoritatea cazurilor, nu au un tratament specific, ci beneficiază doar de o serie de măsuri paliative care permit ameliorarea stării pacienților. [16].

În anul 2014, Planul Național pentru Boli Rare a fost integrat în Strategia Naţională de Sănătate Publică 2014-2020 [5].

\section{CONCLUZII}

Furnizarea de servicii integrate poate ameliora gestionarea afecțiunilor cronice și, implicit, a bolilor rare, iar programele de sănătate pot contribui la identificarea şi partajarea modalităților optime de a îngriji pacienții.

Înființarea și consolidarea rețelelor de referință pot contribui la dezvoltarea capacității de intervenţie, la împărtăşirea bunelor practici, la instituirea unor standarde comune și la promovarea intervențiilor bazate pe dovezi.

Dezvoltarea registrelor de boală este o necesitate stringentă pentru elaborarea unei strategii coerente în implementarea soluțiilor de intervenție în problematica bolilor rare și genetice.

Abordarea în echipă multidisciplinară a cazuisticii bolilor rare și genetice reprezintă o soluție de intervenție în timp util, cu scopul de creștere a accesului pacienților la servicii medico-sociale de calitate.

Este necesar ca Ministerul Sănătății să consolideze programul de instruire pentru personalul din rețeaua de asistență medicală comunitară și să sprijine dezvoltarea rețelei de asistență medicală comunitară în realizarea managementului de caz al bolilor rare.

\section{BIBLIOGRAFIE}

1. Onofrei LM. Asistența medicală comunitară în România: Prezent și perspective. Available at: https://revmedfam.ro/asistenta-medicalacomunitara-in-romania-prezent-si-perspective/.

2. OUG nr. $18 / 2017$ privind asistenţa medicală comunitară aprobată prin Legea 180/ 2017. Monitorul Oficial nr. 154/1 martie 2017.

3. Ghinescu M. Abordarea integrată a pacientului în cadrul procesului de nursing comunitar. Managementul de caz. Acta Medica Transilvanica 2010;2(1):7-9.

4. Recomandarea Consiliului din 8 iunie 2009 privind o acțiune în domeniul bolilor rare 2009/C 151/02 Jurnalul Oficial al Uniunii 
Europene. Available at: https://eur-lex.europa.eu/legal content/RO/ TXT/HTML/?uri=CELEX:32009H0703(02)\&from=EN

5. Strategia naţională de sănătate 2014-2020, aprobată prin Hotărârea Guvernului nr. 1.028/2014. Monitorul Oficial al României, Partea I, nr. 891/8 decembrie 2014.

6. HG nr. 324/2019 pentru aprobarea Normelor metodologice privind organizarea, funcţionarea şi finanţarea activităţii de asistenţă medicală comunitară. Monitorul Oficial nr. 458/7 iunie 2019.

7. HG nr. 459/2010 pentru aprobarea standardului de cost/an pentru servicii acordate în unitățile de asistență medico-sociale și a unor normative privind personalul din unitățile de asistență medico-socială și personalul care desfășoară activități de asistență medicală comunitară. Monitorul Oficial nr. 340/21 mai 2010.

8. Ghinescu M. Serviciile de sănătate din comunităţile defavorizate inclusiv etnia romă. Acta Medica Transilvanica 2008;2(1):14-20.
9. https://insp.gov.ro/sites/cnepss/wp-content/uploads/2016/01/ Informare-Campanie-Boli-Rare-2017.pdf.

10. https://ec.europa.eu/commission/presscorner/detail/ro/IP_17_323.

11. https://www.scoalapacientilor.ro/diagnosticul-genetic-al-bolilor-rareunde-se-fac-teste/.

12. https://ec.europa.eu/health/sites/health/files/ern/docs/2017_ brochure_ro.pdf.

13. http://www.orpha.net/national/RO-RO/index/despre-boli-rare/.

14. https://www.eurordis.org/IMG/pdf/RO-Eurordis-Presentation-Colour. pdf.

15. https://ec.europa.eu/eurostat/statistics-explained/index. php?title=Causes_of_death_statistics/ro.

16. https://www.bolilerare.ro/ce-sunt-bolile-rare/. 